\title{
Post-Synthetic Modification of a Network Polymer of Intrinsic Microporosity and its Hydrogen Adsorption Properties
}

D. Ramimoghadam ${ }^{\text {a }}$, L. Naheed ${ }^{\text {a }}$, S.E. Boyd ${ }^{\text {, }}$ C. L. Brown ${ }^{\text {b }}$, T.A. Webb ${ }^{\mathrm{a}}$, E. MacA. Gray ${ }^{a}$, C. J. Webb年*

${ }^{a}$ Queensland Micro- and Nanotechnology Centre, Griffith University, Nathan 4111, Australia

${ }^{b}$ Environmental Futures Research Institute, Griffith University, Nathan 4111, Australia *Corresponding author email: j.webb@griffith.edu.au

\footnotetext{
${ }^{1}$ Now at Rocket Lab, 25 Levene PI, Mount Wellington, Auckland New Zealand
} 
Table S1. Elemental analysis of the hydrated polymer (HATN-PIM) including potassium and chlorine

\begin{tabular}{|l|l|c|c|c|c|c|c|c|}
\hline NAME & REPEAT UNIT & $\mathbf{C} \%$ & $\mathbf{H} \%$ & $\mathbf{N \%}$ & $\mathbf{O} \%$ & $\mathbf{C l} \%$ & $\mathbf{K} \%$ & $\mathbf{P d \%}$ \\
\hline \multirow{2}{*}{$\begin{array}{l}\text { HATN- } \\
\text { PIM }\end{array}$} & $\begin{array}{l}\text { Calculated hydrated } \\
\text { polymer containing K and } \\
\mathrm{Cl}\end{array}$ & 65.90 & 4.19 & 8.31 & 14.24 & 3.50 & 3.86 & - \\
\cline { 2 - 9 } & Experimental & 62.43 & 4.65 & 8.62 & - & 0.82 & 0.32 & - \\
\hline
\end{tabular}


Figure S1. Full FTIR spectra of HATN-PIM and HATN-PIM-Pd
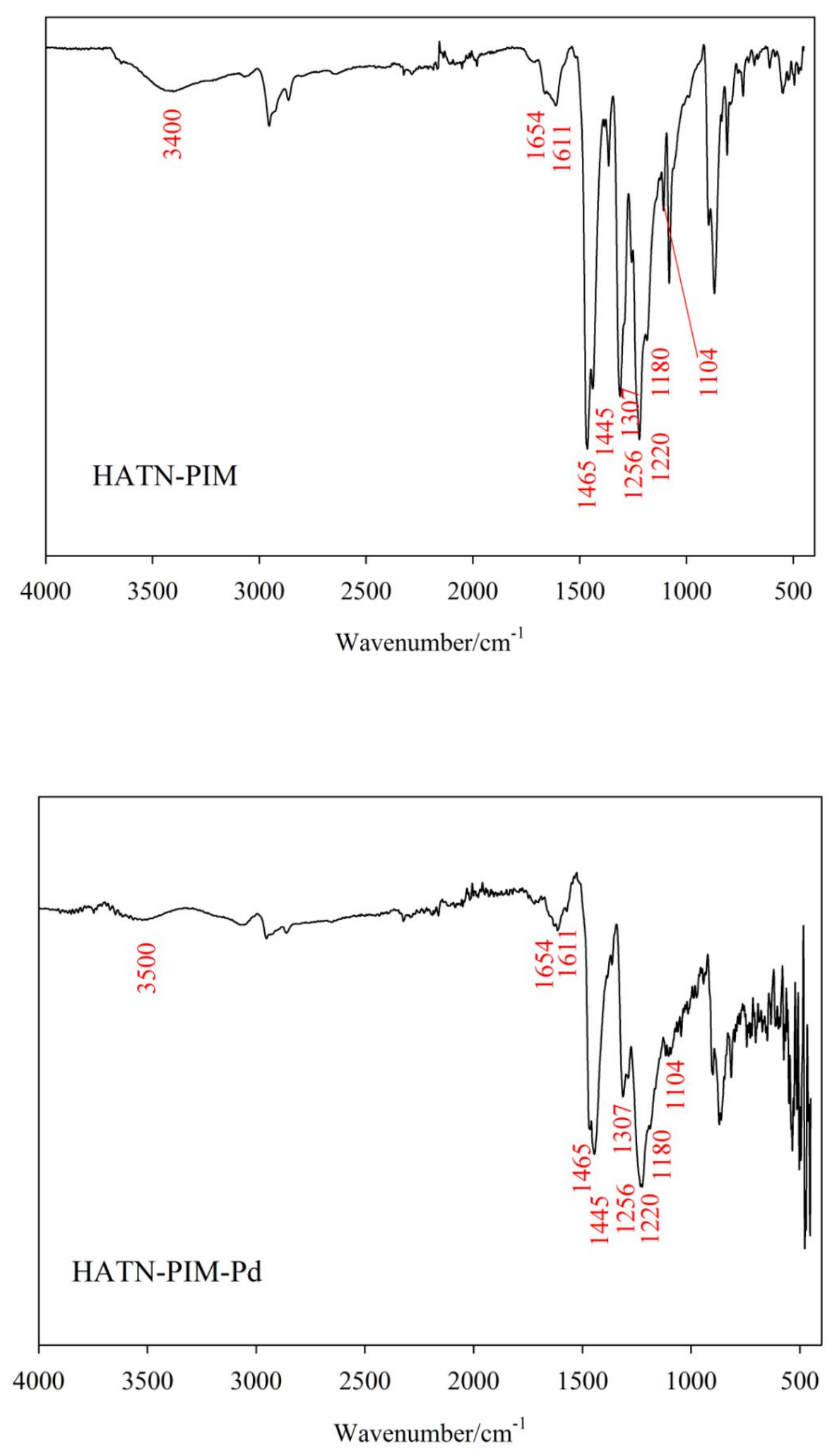
Figure S2. The high-resolution XPS spectra of C1s for HATN-PIM

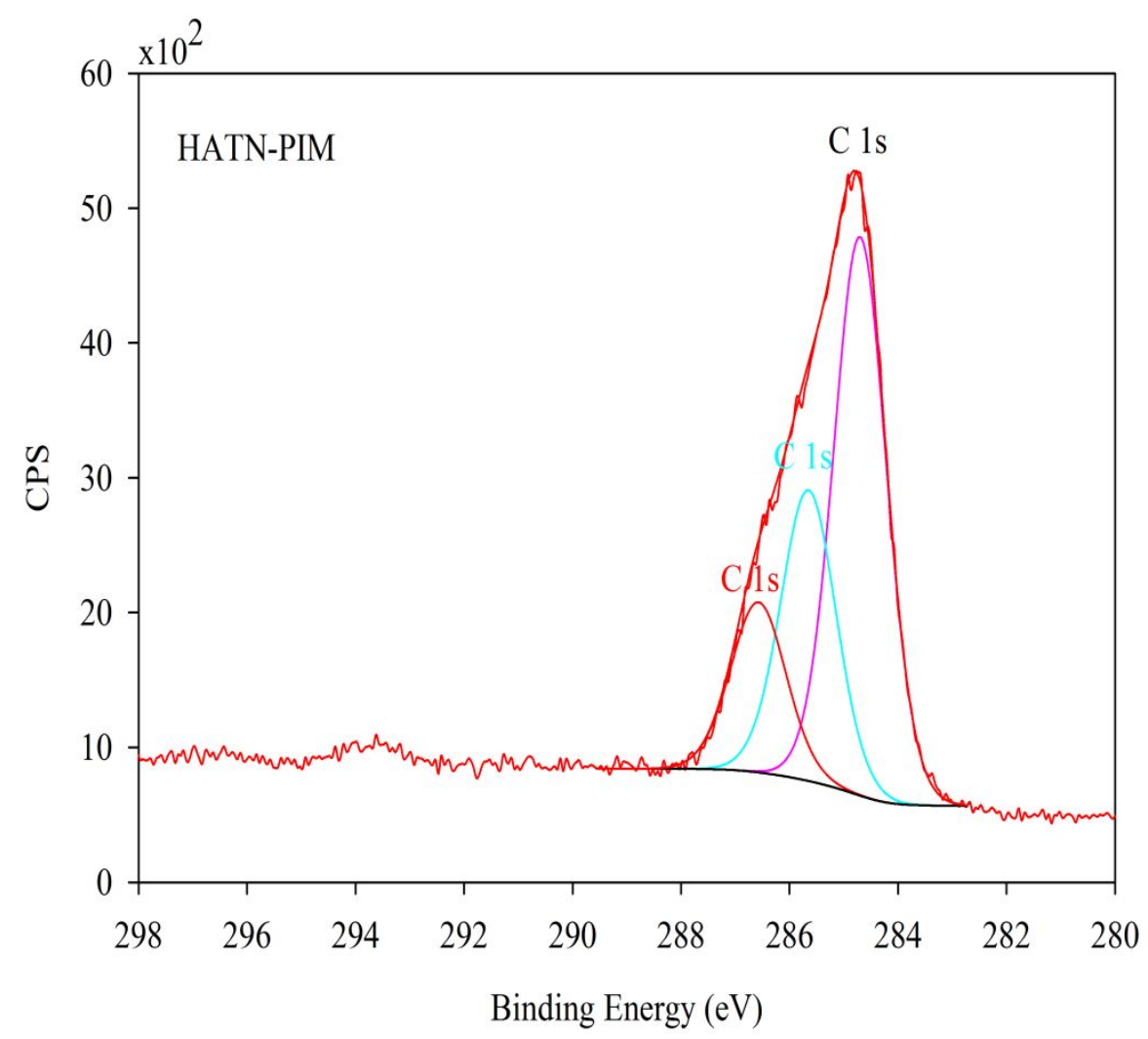

